\title{
A inatingível meta do intangível e as consequências sociais: do The True Cost à Moda Livre
}

\author{
The unattainable goal of intangible assets and the social consequences: \\ from The True Cost to Free Fashion
}

\section{El objetivo inalcanzable de los activos intangibles y las consecuencias sociales: desde The True Cost hasta la Moda Libre}

\author{
Patrícia Golçalves Saldanha | patsaldanha@gmail.com \\ Universidade Federal Fluminense. Programa de Pós-graduação em Mídia e Cotidiano. Laboratório de Investigação de \\ Comunicação Comunitária e Publicidade Social (Laccops). Niterói, RJ. Brasil. \\ Eduardo Aguiar de Assis | eduardoassis@globo.com \\ Universidade Federal Fluminense. Programa de Pós-graduação em Mídia e Cotidiano (PPGMC). Niterói, RJ. Brasil.
}

\section{Resumo}

O presente artigo pretende refletir teoricamente sobre a busca desmedida da elevação de valor de marcas de grandes empresas do segmento fast fashion em contraste com as consequências sociais geradas para a própria sociedade que consome tais marcas. A reflexão se dá a partir do que Max Weber chama de "novo espírito do capitalismo", com base no conceito de "capital imaterial" de André Gorz e articulada ao documentário sobre a indústria da moda The True Cost. Na contrapartida do cenário da aquisição exacerbada, vale destacar o surgimento e a propagação da publicidade social como uma via alternativa que visa possibilitar o equilíbrio entre os atores da cadeia de produção a exemplo do que vem sendo chamado de comércio justo.

Palavras-chave: consumo de marca; capital imaterial; valor intangível; publicidade social; comércio justo; consequências sociais.

\begin{abstract}
This article aims to reflect theoretically on the unrestrained pursuit of valorization of brands of large companies in the segment fast fashion, in contrast to the social consequences generated for the society itself that consumes products of these same brands.The starting point for analysis is what Max Weber calls the "new spirit of capitalism", based on the André Gorz's concept of “intangible capital", and on the documentary The True Cost about the fashion industry. In contrast with the exacerbated consumerism, it is important to mention the emergence and propagation of social advertising as an alternative route that aims to provide the balance between all the people involved in the production chain, like what has been called fair trade.
\end{abstract}

Keywords: brand consumption; immaterial capital; intangible value; social advertising; fair trade; social consequences. 


\section{Resumen}

Este artículo tiene como objetivo reflexionar teóricamente sobre la busca desenfrenada del valor de elevación de marcas de grandes empresas en el segmento de fast fashion, en contraste con las consecuencias sociales generadas para la misma sociedad que consume ese tipo de marcas. La reflexión parte de lo que Max Weber llama "nuevo espírito del capitalismo", basado en el concepto de "capital inmaterial" de André Gorz y en el documentario acerca de la industria de la moda The True Cost. En contrapartida a las compras excesivas, vale la pena señalar la aparición y propagación de la publicidad social como una ruta alternativa que tiene como objetivo permitir el equilibrio entre los actores de la cadena de producción como el ejemplo dado por el que se ha llamado comercio justo.

Palabras clave: consumo de marca; capital inmaterial; valor intangible; publicidad social; comercio justo; consecuencias sociales.

\footnotetext{
Contribuição dos autores:

Concepção e desenho do estudo: Patrícia Gonçalves Saldanha e Eduardo Aguiar de Assis.

Aquisição, análise ou interpretação dos dados: Patrícia Gonçalves Saldanha e Eduardo Aguiar de Assis.

Redação do manuscrito: Patrícia Gonçalves Saldanha e Eduardo Aguiar de Assis.

Revisão crítica do conteúdo intelectual: Patrícia Gonçalves Saldanha e Eduardo Aguiar de Assis.
}

Declaração de conflito de interesses: Os autores declaram não existir conflito de interesse referente à elaboração do artigo.

Fontes de financiamento: Não há.

Considerações éticas: Este estudo foi realizado durante a disciplina de Publicidade Social do Programa de Pós-graduação em Mídia e Cotidiano da Universidade Federal Fluminense oferecida no primeiro semestre de 2016 e continuado no Laboratório de Investigação de Comunicação Comunitária e Publicidade Social (Laccops) do Programa de Pós-graduação em Mídia e Cotidiano da Universidade Federal Fluminense.

Agradecimento/Contribuições adicionais:

Histórico do artigo: Submetido: 08.abr.2016 | Aceito: 18.jul.2016 | Publicado: 30.set.2016.

Licença CC BY-NC atribuição não comercial. Com essa licença é permitido acessar, baixar (download), copiar, imprimir, compartilhar, reutilizar e distribuir os artigos, desde que para uso não comercial e com a citação da fonte, conferindo os devidos créditos de autoria e menção à Reciis. Nesses casos, nenhuma permissão é necessária por parte dos autores ou dos editores. 


\section{Introdução}

A partir da entrada do novo 'espírito' do capitalismo suscitado por Max Weber, cria-se uma outra cultura de consumo que estabelece o fim da relação inicial de equivalência do valor de troca entre mercadorias. Pela perspectiva de André Gorz, com a identificação dos atributos simbólicos dos bens de consumo, prioriza-se seu valor imaterial. Não sendo mais possível identificar horizontes para o intangível, seus métodos para se chegar às metas tornam-se desconhecidos até os dias de hoje.

A nova ordem econômica passa a ser sustentada por alicerces subjetivos e mensurada por estimativas cada vez mais discrepantes em relação aos ativos tangíveis de uma corporação. Novos cenários são colocados em prática a partir da terceirização do capital material fixo e a busca pelo lucro incessante do capitalismo moderno gera uma série de consequências negativas nas esferas sociais e econômicas, a exemplo de doenças físicas e psíquicas.

Nesse cenário, quem lucra, quem (sobre)vive e quem morre? Que tipos de consumidores nascem? Qual a meta, quando o objetivo é consumir? A publicidade social se apresenta como uma alternativa em meio a esse cenário. $\mathrm{O}$ artigo examina matérias jornalísticas sobre o assunto veiculadas na internet entre o segundo semestre de 2014 e o primeiro semestre de 2015; analisa algumas cenas do documentário The True Cost $(2015)^{1 ;}$ e fundamenta sua estrutura teórica em artigos científicos e literatura estruturante sobre a temática. Acrescentam-se ao acervo de consulta, os relatórios globais de rankings de valor de marca emitidos entre janeiro e maio de 2015 pelas duas principais consultorias mundiais, Brand Finance e MillwardBrown, e pela avaliação da revista Forbes. Por fim, para complementar o processo de análise, foi fundamental, para referenciar o trabalho, a utilização do balanço patrimonial ${ }^{2}$ da empresa líder no valor de marca divulgado em setembro de $2014^{3}$, já que calcula a relação entre o ativo tangível e o intangível.

Vale ressaltar que o trabalho é de natureza teórica e encontra-se em fase inicial da pesquisa geral do Laccops - Laboratório de Investigação de Comunicação Comunitária e Publicidade Social do Programa de mestrado em Mídia e Cotidiano da Universidade Federal Fluminense. Desta forma, objetiva-se levantar indagações e direcionamentos sobre a abrangência do conceito de publicidade social para contribuir com a propagação de iniciativas de comércio justo4.

\section{A inatingivel meta do valor intangível: quem lucra com o processo de valoração da marca?}

Desde a Revolução Industrial, o capitalismo vem consolidando suas características mais agressivas no que tange à cultura do consumo e afetando a sociedade de forma degradante. O mundo globalizado e os novos hábitos de consumo não trouxeram avanço a determinadas lutas históricas. Em tempos de intolerância religiosa, lutas por direitos civis de classes minoritárias e disputas econômicas, o capitalismo moderno parece não levar em conta ou atribuir o merecido destaque à cadeia de produção que tem viabilizado a cultura do consumo, sobretudo, na sociedade ocidental. Segundo Bauman ${ }^{5}$, trata-se na atualidade de uma sociedade de consumo. Nesse sentido, temos em mente algo mais que a observação trivial de que todos os membros dessa sociedade consomem; todos os seres humanos, ou melhor, todas as criaturas vivas "consomem" desde tempos imemoriais. O que temos em mente é que a nossa sociedade é de consumo no sentido, similarmente profundo e fundamental, de que a sociedade dos nossos predecessores, a sociedade moderna nas suas camadas fundadoras, na sua fase industrial, era uma "sociedade de produtores". [...] A diferença entre os dois estágios da modernidade é "apenas" de ênfase e prioridades - mas essa mudança de ênfase faz uma enorme diferença em praticamente todos os aspectos da sociedade, da cultura e da vida individual ${ }^{5}$.

Principalmente porque $o$ ato de consumir não se restringe à relação de compra, mas tem um sentido ampliado. Embora tenha sido originado na troca de mercadorias de valor equivalente, atualmente, é 
possível perceber em atos simples como a ida com amigos a um bar que, também, estamos consumindo a eletricidade do estabelecimento, os talheres, o ar-condicionado, os serviços do cozinheiro, do copeiro etc. Somos impactados por imagens imbuídas de valores simbólicos, desde o primeiro instante em que acordamos, pelas marcas que nos cercam, como as do despertador, da pasta de dentes, do meio de transporte utilizado para ir trabalhar e assim sucessivamente até a hora de dormir. Acrescentando à perspectiva de Bauman, somos interpelados no cotidiano em praticamente todos os aspectos da vida individual, mas também em nossa vida coletiva, e é nesse sentido que o consumo pode ser pensado de forma ampliada. Exatamente por isso, torna-se premente refletir as medidas de tal ampliação pois, quando fazemos escolhas relativas a produtos ou serviços, existe vida humana trabalhando na manufaturação de tais produtos ou no desenvolvimento de tais serviços. É necessário, portanto, compreender como as concepções de trabalho foram se modificando ao longo do tempo e como tais relações se articulam com os modos de produção material ou imaterial que vão gerar consumo.

Considerado um dos fundadores do estudo moderno da sociologia, Max Weber estuda, em $A$ ética protestante e o "espírito" do capitalismo $o^{6}$, o processo de racionalização e desencantamento do mundo a partir da mudança da concepção tradicional de trabalho para a concepção sob a ótica protestante. Para Weber, o mundo dominado pela religião católica antes da Revolução Industrial não previa a ideia de acúmulo de bens. $\mathrm{O}$ trabalho era, simplesmente, um meio de garantir subsistência e atendimento às necessidades tradicionais, logo, a oração e a concessão do indulto seriam suficientes para garantir um lugar no "reino dos céus". A partir do protestantismo, a visão de trabalho como a finalidade da existência humana interligada com propósitos divinos promove a entrada do que ele chama de um novo "espírito" do capitalismo uma vez que, durante aquele período, o ser social, extremamente dedicado aos novos modos de produção, não encontrava tempo nem espaço para pecar.

Em sua obra, Weber analisa uma série de fatos históricos e declarações de autores para conceituar o “novo ‘espírito’ do capitalismo”, permeados pela perspectiva financeira e pela noção de acúmulo de capital, em que ter honra se equipara diretamente a cumprir seus acordos financeiros. O propósito seria, como a premissa de vida do milionário Jacob Fugger que, conforme cita o pensador, "queria ganhar enquanto pudesse", uma "conduta de vida eticamente coroada" ${ }^{6}$.

Em contraste com essa visão, encontramos uma variedade de obras literárias e audiovisuais na atualidade que tratam da "suspensão do cotidiano" como meio para identificar os problemas atuais da cultura do consumo capitalista. Tal ação de "suspensão do cotidiano" se faz necessária para compreensão da realidade capitalista na qual estamos inseridos, já que o cotidiano é o lugar onde o homem existe "inteiro" e está imerso. Com a entrada desse "espírito do capitalismo", a nova concepção da vida tendo o trabalho e o acúmulo de bens como finalidade parece simplesmente irracional para Weber: o ser humano em função do ganho como finalidade da vida. Não mais o ganho em função do ser humano como meio destinado a satisfazer suas necessidades materiais. [...] ganhar dinheiro e sempre mais dinheiro, no mais rigoroso resguardo de todo gozo imediato do dinheiro ganho, algo completamente despido de todos os pontos de vista eudemonistas ou hedonistas ${ }^{i}$ e pensado tão exclusivamente como fim em si mesmo, que, em comparação com a "felicidade" do indivíduo ou sua "utilidade", aparece em todo caso como inteiramente transcendente e simplesmente irracional. O ser humano em função do ganho como finalidade da vida, não mais o ganho em função do ser humano como meio destinado a satisfazer suas necessidades materiais.

Para Weber, o ganho de dinheiro como fim se torna o motivo condutor do capitalismo na economia moderna, tendo em vista que a obsessão pelo ganho sempre existiu em todos os períodos da história, como a guerra, a pirataria, o livre-comércio sem regulação. Com a queda do que ele chama de "tradição" e o

i Eudemonismo é a doutrina que considera a busca de uma vida feliz, seja em âmbito individual seja coletivo, o princípio e fundamento dos valores morais, julgando eticamente positivas todas as ações que conduzam o homem à felicidade. 0 hedonismo julga o prazer como o supremo bem da vida humana. 
surgimento do livre lucro, as consequências dessa relação ultrapassaram os limites éticos, atingindo um caráter deontológico, com base em outra noção de moral necessária para nortear as ações que deveriam ser executadas no novo contexto. Considerando que deontologia ${ }^{8}$ é a ciência ou tratado dos deveres de um ponto de vista empírico, como conceber o caráter deontológico no mundo globalizado da sociedade capitalista? Parece clara a necessidade de se estabelecer uma ética para regular essa busca desmedida do lucro que gera práticas abusivas, como exemplificado por Weber ao discorrer sobre a aplicação do salário por tarefa pelos empresários para obter de "seus" operários o máximo possível de rendimento. Com o interesse do empresário em acelerar a colheita em determinadas épocas do ano, o aumento do pagamento por tarefa não teve o resultado esperado de maior produtividade: ganhar mais o atraía menos que o fato de trabalhar menos. Ele não se perguntava quanto posso ganhar por dia se render o máximo de trabalho? E sim: quanto devo trabalhar para ganhar a mesma quantia e que cobre as minhas necessidades tradicionais? O ser humano não quer "por natureza" ganhar sempre mais dinheiro, mas simplesmente viver do modo como está habituado a viver e ganhar o necessário para tanto. Para atingir seus objetivos, o empresário recorreu ao método inverso por meio da redução dos salários a fim de obrigar o trabalhador a produzir mais do que antes para manter o mesmo ganho.

É possível constatar que a relação de exploração descrita por Weber em 1864 permanece atual nos dias de hoje. Haja vista a forma seletiva do capitalismo para recrutar os atores sociais de que necessita com agilidade e facilidade em todas as regiões do mundo. O que é ilógico, na visão de Weber, "alguém tomar como fim de seu trabalho na vida exclusivamente a ideia de um dia descer à sepultura carregando enorme peso material em dinheiro e bens"6

Contudo, o sistema econômico gerado pela conjuntura capitalista transparece como tema indiscutível pelos controladores do poder e ausente de alternativas, concentrado na "vocação" de ganhar dinheiro. As categorias da economia começam a priorizar o conhecimento reordenando as noções de trabalho, valor e capital, sendo esses os objetos de estudo de André Gorz em O Imaterial, em que emprega o conceito de "capital humano" e a coexistência de muitos modos de produção. Como entender as consequências dessa mudança no cenário de produção capitalista que redimensiona valor entre o material e o simbólico? O que fez com que a marca valesse mais que o produto? O trabalho em sua forma imediata, mensurável e quantificável, deverá deixar de ser a medida da riqueza criada. Esta "dependerá cada vez menos do tempo de trabalho e da quantia de trabalho fornecida"; ela dependerá cada vez mais "do nível geral da ciência e do progresso da tecnologia". (...) O "processo de produção" não poderá mais ser confundido como um "processo de trabalho". O conhecimento é considerado como a "força produtiva principal" ii.

Com isso, reduzem-se as relações de trabalho convencionais. Os valores de troca das mercadorias não se equivalem mais por não serem definidos pela quantidade de tempo gasto na produção, mas pela quantidade de conhecimento e atributos simbólicos agregados.

Para vislumbrar "como o conhecimento é transformado em capital imaterial e como a valorização desse capital grandemente fictício é assegurada pela edificação de posições de monopólio”, Gorz cita o conceito de new economy de Jeremy Rifkin: a novidade de Rifkin é a nova concepção do que dá "valor" aos produtos ou do que os torna vendáveis com o máximo de lucro. Esse máximo depende da capacidade que uma firma tem de se ligar a uma clientela, de fazê-la comprar imediatamente, e sem maiores custos, as últimas novidades; de persuadi-la do "valor" incomparável do que lhe oferece 9.

Grandes exemplos dessa relação de compra imediata na atualidade são as enormes filas na frente de lojas da Apple em cidades como Hong Kong e Tóquio, entre outras pelo mundo, uma semana antes do lançamento de novos modelos de iPhones. O objetivo não é ter um telefone, mas sim adquirir um valor materializado no novo modelo do produto na data de lançamento antes de todos do seu núcleo social. Vale ressaltar que

ii Marx K. Grundrisse. Berlim: Dietz Verlag, 1953: 587-599 apud ${ }^{9}$. p. 15-16. 
as diferenças funcionais básicas entre um modelo e outro não são tão significativas, com ressalvas, é claro, em relação à qualificação de processadores, capacidade de armazenamento etc. A condição imaterial do produto se torna prioritária sobre a objetividade material. Há uma ampliação do valor simbólico, que se consubstancia na força da logomarca, inserido na conjuntura social e sobreposto à sua utilidade prática. Os aspectos relacionados à materialidade são colocados em segundo plano, pois não são mais vantajosos pela perspectiva econômica. Esse paradoxo mercadológico inicia o processo de terceirização dos setores de produção material de grandes corporações, como a grande marca de calçados Nike, por exemplo, que não possui fábricas. Seus escritórios concentram os serviços de branding (gestão das marcas) e design dos produtos, totalmente enfocados no desenvolvimento de valores e atributos simbólicos para projetar uma imagem que gere identificação com o consumidor. Assim, uma proporção rapidamente crescente de firmas prefere alugar seu capital fixo material (prédios, instalações, máquinas, meios de transporte) a ser proprietária dessas coisas. Nos Estados Unidos, um terço das máquinas, das instalações e dos meios de transporte é alugado e 80\% das empresas alugam sua infraestrutura a duas mil agências especializadas. Um terço das indústrias terceirizou mais da metade das suas atividades de produção. IBM e Compaq [...] contrataram a mesma firma, Ingram, para a construção, a entrega e a fatura de seus computadores 9 .

Com a terceirização da produção e do capital fixo material, cria-se um novo parâmetro na cadeia de produção: a desvalorização da mão de obra gerando atividades análogas ao trabalho escravo. O capital material é entregue aos "parceiros" contratados pela corporação responsável pela marca, que explora os trabalhadores de países subdesenvolvidos por meio de revisões constantes das cláusulas contratuais e reduz os custos de produção de forma agressiva, aumentando cada vez mais sua margem de lucro. A terceirizada não tem como não vender ao preço reduzido imposto pela contratante por ser dependente economicamente desse "cliente". "O trabalho e o capital fixo material são desvalorizados e frequentemente ignorados pela Bolsa, enquanto o capital imaterial é avaliado em cotações sem base mensurável" ${ }^{9}$. A ausência de base mensurável cria uma nova problemática na conjuntura do capitalismo moderno.

Mesmo na condição subjetiva em que os atributos simbólicos e imateriais são avaliados, eles passam a ser representados pelas marcas das grandes corporações e também se tornam bens a serem geridos como ativos estratégicos ocupando posições singulares na nova ordem do mercado, podendo ser comercializados. A gestão de marcas se torna uma ferramenta importante para gerir o ativo intangível e, como tal, inicia crescentes cotações na bolsa de valores, tendo as melhores marcas como garantia de qualidade. A American Marketing Association (AMA) define marca como "um nome, termo, sinal símbolo ou combinação dos mesmos, que tem o propósito de identificar bens de um vendedor ou grupo de vendedores e de diferenciálos de concorrentes" ${ }^{\prime \prime}$. A concorrência gera rankings de valor das marcas por diversas consultorias especializadas e levanta questões quanto ao caráter subjetivo de tais medições, já que elas são compostas pela possibilidade de lucros futuros a partir da imagem da instituição posicionada no mercado.

Sendo assim, quais as metas das possíveis classificações das categorias e das marcas? Já que os valores não param no logotipo e/ou na representação simbólica da marca e a especulação se torna mais válida e possui mais força na economia mundial que os ativos tangíveis. Observa-se uma meta de caráter inatingível, já que tal meta está sempre no futuro, onde não está clara a linha de chegada. Como explicitado por André Gorz quando responde à questão sobre o valor da Microsoft: "tudo quanto se queira" .

Contudo, a divulgação de rankings, em alguma medida, foi alvo de súbito interesse ordinário, social e comercial. Embora não se tenha uma linha de chegada, nota-se que o ponto de partida se deu no capitalismo do consumo. Com tantas catalogações, posicionamentos e crescimento sem controle, especular se tornou a meta. Mesmo em 2010, quando foi estabelecida a ISO 10668 - Global Standard for Brand Valuations ${ }^{\mathrm{iii}}$, que

iii SO 10668 - Global Standard for Brand Valuations - A norma estabelece que os avaliadores devem verificar três aspectos: análise legal - verificação dos direitos legais de proteção da marca; análise comportamental - verificação e opinião sobre o comportamento de todos os interessados pela marca; a análise financeira - três abordagens para calcular o valor da marca que é mercado, custo ou renda ${ }^{12}$ ). 
define os padrões mínimos que devem ser seguidos quanto aos procedimentos e métodos utilizados para valorização de qualquer marca ${ }^{11}$, a discrepância nos rankings divulgados continuou latente, até mesmo entre consultorias especializadas num curto espaço de tempo. Podemos observar tal discrepância ao analisarmos a variância das posições no ranking e valores de mercado de três marcas citadas no documentário The True Cost $^{1}$ selecionadas na tabela abaixo, sendo uma de calçados e duas de vestuário:

Quadro 1 - Posição no ranking e valor da marca de três corporações citadas no documentário The True Cost

\begin{tabular}{|c|c|c|c|c|}
\hline $\begin{array}{l}\text { Órgão responsável } \\
\text { pelo ranking }\end{array}$ & Mês/ano & Nike & H\&M & Zara \\
\hline $\begin{array}{l}\text { Brand Finance Global } \\
500^{12}\end{array}$ & Fevereiro 2015 & $\begin{array}{c}31^{\circ} \\
\text { US } \$ 24,1\end{array}$ & $\begin{array}{c}71^{\circ} \\
\text { US\$ } 14,7\end{array}$ & $\begin{array}{c}142^{\circ} \\
\text { US } \$ 8,6\end{array}$ \\
\hline $\begin{array}{l}\text { MillwardBrown } \\
\text { BrandZ Top } 100 \\
\text { Most Valuable Global } \\
\text { Brands }^{13}\end{array}$ & Abril 2015 & $\begin{array}{c}28^{\circ} \\
\text { US } \$ 29,7\end{array}$ & $\begin{array}{c}75^{\circ} \\
\text { US\$ } 13\end{array}$ & $\begin{array}{c}42^{\circ} \\
\text { US\$2 } 22\end{array}$ \\
\hline $\begin{array}{l}\text { Forbes' list of } \\
\text { the World's Most } \\
\text { Valuable Brands }{ }^{14}\end{array}$ & Maio 2015 & $\begin{array}{c}18^{\circ} \\
\text { US\$ } 26,3\end{array}$ & $\begin{array}{c}33^{\circ} \\
\text { US\$ } 15,3\end{array}$ & $\begin{array}{c}58^{\circ} \\
\text { US } \$ 9,4\end{array}$ \\
\hline
\end{tabular}

Fonte: Elaborada pelos autores a partir dos dados divulgados pelos órgãos mencionados (US\$ valores em bilhões de dólares).

Os valores de marca e posicionamento foram extraídos dos relatórios globais de valor da marca das consultorias especializadas Brand Finance e MillwardBrown, além da lista mundial divulgada anualmente pela revista Forbes. Os dados foram divulgados entre fevereiro e maio de 2015 e apresentam elevadas variações, tanto financeiras quanto de posicionamento, num curto espaço de tempo, como por exemplo a marca Zara, que em fevereiro ocupava a $142^{\mathrm{a}}$ posição no ranking da Brand Finance, sendo avaliada em 8,6 bilhões de dólares. Dois meses depois, assumiu a $42^{\mathrm{a}}$, aumentando $155 \%$ o valor de sua marca, atingindo a marca de 22 bilhões de dólares e, no mês seguinte, reduziu o valor para 9,4 bilhões de dólares, caindo 16 posições no ranking.

Mesmo com metodologias relativamente diferentes, sempre há uma proximidade maior com a similaridade baseada na ISO 10668 e nas análises financeira, de demanda e da concorrência, bem como nos lucros futuros esperados. Há, em alguns casos, métricas consideradas inovadoras pelo mercado como o Índice de Conexão Humana da Marca (ICHM), lançado em 2009 pela consultoria Sart Dreamaker, que passou a levar em consideração o impacto emocional dos consumidores em relação à marca por meio da análise de 34 pontos de conexão entre a marca e o consumidor divididos em quatro dimensões: atenção, relevância, significado e confiança. Contudo, a variância nas estimativas de valor divulgadas não se justifica e reforça, ainda mais, a primazia pelo valor do imaterial. Inclusive, na perspectiva contábil, já que as empresas registram o intangível no seu balanço patrimonial desde que tenham um laudo de avaliação. Em 1999, o capital material da indústria americana não representava mais do que um terço de toda a capitalização da bolsa de valores. Segundo um estudo sueco citado por Rifkin, o capital imaterial [...] da maior parte das empresas, atingia no mesmo ano uma capitalização na bolsa de cinco a dezesseis vezes mais elevada do que a atingida por seu capital material e financeiro. [...] O interesse da bolsa pelos "ativos imateriais" também chamados “intangíveis", foi, na segunda metade dos anos 1990, a excrescência mais espetacular de uma alta da bolsa que não teve precedentes. [...] Essa reengineering [...] havia consistido em aliviar as estruturas produtivas e os fatores de produção: a organização, o aparelho de gestão e de administração, o capital fixo, os efetivos, os custos salariais diretos e indiretos, e os custos de comercialização. [...] A alta do valor dos intangíveis poderá continuar a se acelerar [...]. O investimento inicial pouco importa. [...] O que conta não é necessariamente o trabalho de invenção, é o que é necessário para vender essa invenção antes que os 
outros tenham encontrado ou copiado o que você fez. O que conta, em suma, é principalmente transformar a invenção em mercadoria, e pô-la no mercado como um produto de marca patenteada ${ }^{11}$.

Gorz cita Enzo Rullani ao dizer que o valor de um conhecimento "é ligado à capacidade de monopolizar o direito de se servir dele"11. Ou seja, para os produtos que possuem forte presença imaterial, a rentabilidade econômica se dará no que ele chama de "monopólio do conhecimento". Ao deter esse monopólio, as mercadorias associadas a essa marca e/ou produto também se tornarão rentáveis e terão valor simbólico agregado. As empresas que conseguem inovar e mercantilizar suas inovações estarão sempre elevando seu valor de mercado. Essa associação para criação de rendimentos de monopólio fica clara no caso da multinacional de agricultura e biotecnologia Monsanto, que patenteou sementes geneticamente modificadas (transgênicas) respondendo a $70 \%$ a $100 \%$ do mercado e aumentando o custo $17.000 \%$ conforme apresentado no documentário The True Cost. Muitas vezes, a relação simbólica e o poder de monopólio se tornam tão fortes como a letra "M" da rede Mc Donald `s, que, segundo pesquisa do livro Fast Food Nation ${ }^{15}$, é reconhecida por $88 \%$ da população, em contraste com $54 \%$ que associaram a cruz a Jesus Cristo, já que o Cristianismo não é difundido em 100\% do mundo.

O poder do intangível muitas vezes ultrapassa o valor do tangível. O capital fixo imaterial toma vantagem na corrida pela incessante busca de elevação de seu valor. Os vínculos emocionais com a marca criam novos tipos de consumidores e redesenham novos contextos culturais na sociedade contemporânea. E enquanto o lucro desmedido supera expectativas, como por exemplo a rede varejista sueca $H \& M$ que obteve um aumento de $19 \%$ acima do previsto no mês de agosto de $2014^{16} \mathrm{e}$ continua a inaugurar mais lojas ao redor do mundo, outros sobrevivem de forma degradante nesse cenário, conforme explanado a seguir.

\section{Quem (sobre)vive pelo valor da marca? As estratégias de disseminação da lógica do consumo fast fashion}

Como foi possível observar, a prática do consumo avança desenfreadamente em praticamente todas as esferas da vida. No entanto, vale destacar que, na indústria da moda, quaisquer barreiras (inclusive as sociais e culturais) que possam vir a obstruir o avanço de circulação de suas mercadorias, são desmanteladas de forma implacável. Além dos lucros advindos dos ativos intangíveis também serem "computados" no balanço patrimonial da empresa e no seu valor de mercado, observa-se no contexto do capitalismo moderno que somente essas corporações, seus empresários e governantes criam novos cenários para aumentar suas margens de lucros. É o caso da Black Friday, inicialmente estabelecida no dia posterior à data mais celebrada do ano nos Estados Unidos, o Thanksgiving, servindo como ponto de partida para as vendas de Natal. O período foi expandido para semanas e exportado para outros países, inclusive para o Brasil, abrangendo todos os tipos de produtos e serviços como postos de gasolina, viagens etc. Atualmente, a cultura do consumo estabelece muitas black fridays ao longo do ano assim como as dezenas de coleções de roupas lançadas ao invés das quatro tradicionais coleções anuais de outrora relacionadas às estações da primavera, verão, outono e inverno. Todavia, vale destacar que, para além de constituir um processo cíclico (ou não) de produção e distribuição de mercadoria, a moda representa um sistema original de regulação e de pressão sociais: suas mudanças apresentam um caráter constrangedor, são acompanhadas de um "dever” de adoção e de assimilação, impõem-se mais ou menos obrigatoriamente a um meio social determinado - tal é o "despotismo" da moda tão frequentemente denunciado ao longo dos séculos. Despotismo muito particular já que sem sanção maior, a não ser o riso, a zombaria e a reprovação dos contemporâneos. Mas, por mais eficazes que possam ter sido, esses meios de conformidade social, em particular nos séculos de honra e de hierarquia, não bastam para explicar os fenômenos de epidemia de moda. Mais fundamentalmente, é em razão do desejo dos indivíduos de se assemelharem àqueles que são considerados superiores, àqueles que brilham pelo prestígio e pela posição, que os decretos da moda conseguem propagar-se: no coração da 
difusão de moda, o mimetismo do desejo e dos comportamentos, mimetismo que, nos séculos aristocráticos e até uma data recente, propagou-se essencialmente de cima para baixo, do superior ao inferior, como já o formulava G. de Tarde ${ }^{17}$.

Seguindo a lógica da moda como sistema de regulação, que sustenta estruturas imperativas do vestuário e que nos tempos hipermodernos tem ícones midiáticos como representantes, o consumidor passa a alterar o seu ritmo de aquisição. No cenário em que a novidade passa a ser imediata para a consolidação do estilo fashion, soma-se a popularização de "mobiles" como ferramentas facilitadoras da realização da compra. Desta forma, cada vez que uma celebridade aparece com uma peça nova, independentemente da coleção que outrora estava "presa" à estação, um clique no celular efetiva a compra num único instante. Segundo Lipovestsky "a cultura de massa é ainda mais representativa do processo de moda do que a própria fashion. Toda a cultura de mass-midiática tornou-se uma formidável máquina comandada pela lei da renovação acelerada, do sucesso efêmero, da sedução, da diferença marginal” ${ }^{\prime 1}$. Assim, percebe-se uma mudança de cenário, instituída pela indústria têxtil como Moda Rápida (Fast Fashion), é retratada no documentário The True Cost como um dos pilares de sustentação desse novo "espírito" do capitalismo por meio dos caminhos percorridos por cada peça de roupa que vestimos e os impactos sociais e ecológicos provocados com a finalidade única do grande comércio. De acordo com o filme, até os anos 1960, 95\% do vestuário destinado à comercialização nos Estados Unidos eram produzidos no próprio país. Atualmente, são apenas $3 \%$. Os outros $97 \%$ são subcontratados em países em desenvolvimento ou subdesenvolvidos pelo mundo. Isto porque, com a reinvenção da indústria da moda no lançamento de quase 52 coleções ao longo do ano, houve uma deflação no preço das peças de vestuário. Porém, os custos de produção não diminuíram. A saída encontrada pela lógica capitalista foi "terceirizar" a produção em países com economias de baixo custo, abrindo margem para a criação das chamadas "fábricas de exploração" de mão de obra escrava e produzindo um novo tipo de consumidor que deseja a cada semana vestir uma peça de roupa nova.

Cenas em que o consumo exacerbado é explícito, como pessoas correndo e caindo durante a abertura em um dia de black friday das gigantes varejistas H\&M, GAP, Zara, Forever 21 são contrapostas às dificuldades passadas pela costureira Shima apresentada no documentário, de 23 anos, que trabalha em Dhaka desde os 12, e não tem condições de criar sua filha, tendo que levá-la muitos dias para seu local de trabalho insalubre por não ter com quem deixá-la. Na esperança de que a filha tenha um futuro melhor que o seu, já que possui um salário de três dólares por dia, a costureira opta por deixar sua filha junto aos seus familiares em uma aldeia distante por constatar a falta de recursos que garantam sua sobrevivência. Shima faz parte dos mais de 40 milhões de trabalhadores da indústria têxtil ao redor do mundo que sobrevivem em condições indignas e produzem vestuário para grandes marcas ocidentais. Esses "momentos" de consumo propiciados pela lógica capitalista atual fortalecem o cultivo da relação simbólica com a marca e reduzem os atributos materiais do produto em si. Ou seja, o valor imaterial agregado se sobrepõe continuamente como se estivesse num "looping" já que o cidadão possui a urgência em estar constantemente na moda a partir do uso de várias versões da mesma marca. Mesmo que, para isso, se endivide, utilize produtos não originais ou provenientes de mão de obra escrava.

Atender às necessidades básicas não é mais suficiente. É exigido ser o primeiro a ter tal produto, a usufruir determinado serviço com prioridade, e a divulgar tais relações. Para atender à urgência das demandas, impactos sobre a natureza ou consciência social são desconsiderados. Um novo tipo de consumidor surge e, com ele, as consequências. Para o relações públicas vienense Edward Bernays, o capital imaterial produz uma nova espécie de consumidores que não necessitam daquilo que desejam, e não desejam aquilo de que necessitam. O sujeito precisa de um tênis para calçar ou um calçado da marca Nike, por exemplo? Essa é uma questão central na relação de consumo que vem, cada vez mais, sendo estabelecida no cotidiano atual. A partir do vínculo simbólico com a marca, forma-se um novo tipo de consumidor que (sobre)vive em meio ao mercado de produtos falsificados ou roubados, por exemplo, no qual as pessoas querem ter a marca 
e não o produto. Ou seja, consumo imaterial em si é a necessidade e não o objeto. Chega-se ao ponto de não primar pela saúde, como é o caso do uso de óculos fashion não aprovados pelos órgãos certificadores de oftalmologia. Desta forma, percebe-se que o mercado tem sido estimulado pela nova cultura que se naturaliza a cada dia: desloca-se a razão da busca pelo produto da necessidade de uso para a priorizar outro objetivo fim, o consumo pelo consumo. Para o pesquisador Bruno Pompeu, "os significados do consumo [...] estão muito mais preenchidos de significados do que o senso comum pode supor. Na sociedade atual, estar vivo é simplesmente consumir - os que não consomem não existem, são invisíveis, estão mortos”18.

A necessidade de visibilidade por meio do consumo, relatada por Pompeu no trecho acima, fica nítida nas cenas de The True Cost em que aparecem jovens de classe média veiculando vídeos semanais ou diários no YouTube simplesmente para mostrar as peças de roupas recém-adquiridas. Semelhante postagem após postagem, verifica-se que as personagens não são profissionais ou críticas do mercado de moda, são cidadãs comuns, imbuídas da cultura do consumo e imersas na contemplação da variedade pela soma e não pela qualidade do produto. Quer dizer, a acepção de necessidade se afasta a passos largos da noção de uso e passa a pertencer a outra ordem. Nesse sentido, Mary Douglas e Baron Isherwood afirmam que "todos os bens são portadores de significado"19 e os significados se constroem coletivamente. No entanto, a geração dos novos tipos de consumidores não satisfaz suas necessidades, já que a necessidade passa a ser consumir. No caso dos relatos das jovens que aparecem no documentário, em vídeos no YouTube, os significados dos bens adquiridos são restritos ao reforço dos vínculos com a marca e esvaziados das utilidades cotidianas como, por exemplo, vestir um casaco para se aquecer.

Já foi dito que, no contexto econômico do capitalismo moderno, o vínculo com a representação simbólica se torna tão forte, que se cria um mercado de falsificações. Conforme apresenta Pompeu, a relação entre curtir e comprar indica que: mesmo que se tenha comprado o produto, é melhor curtir a fan page da marca, ou o vínculo, embora realizado, corre o risco de não "existir", porque não é exposto. [...] Ainda que o produto comprado seja pirata, seja grosseiramente falsificado, o vínculo com a marca original é também estabelecido e, portanto, pode ter havido consumo ${ }^{18}$.

Para alavancar a produção da quantidade de produtos (originais ou falsificados) suficientes para atender a uma parcela significativa da sociedade do consumo, a mão de obra barata se torna o elemento principal para impulsionar a nova economia. A exploração chega a um nível tão elevado, que causa a morte de entes envolvidos na relação de escravidão e servidão de sua vida em prol do capitalismo.

\section{Quem morre pelo valor da marca? O prejuízo na saúde, o verdadeiro custo do consumo ilimitado}

Salta aos olhos constatar que, mesmo após a globalização e as grandes transformações sociais em suas mais diversas esferas, os $20 \%$ que já eram ricos ficaram mais ricos e a grande parcela restante de pobres ficou mais pobre. Chega a ser antiético observar que, a soma do valor (intangível) das 100 marcas mais valiosas do mundo chega à margem dos US $\$ 3,3$ trilhões de dólares e que o pleito por um salário de US\$ 160 dólares mensais para trabalhadores da indústria têxtil no Camboja se torne um confronto com a polícia local gerando violência, feridos e mortes, conforme cenas de manifestações na cidade de Phnom Penh, apresentadas em The True Cost.

Com a terceirização do capital material fixo a baixo custo, doenças sociais, físicas e psíquicas se relacionam direta e indiretamente nesse contexto do consumo exacerbado, como cenas da incidência de tumores cancerígenos em agricultores de fazendas de algodão sintético pelo uso diário de pesticidas e outros produtos químicos, também observadas no documentário analisado. Pela ordem econômica capitalista e o aumento da produtividade, algumas empresas optam, por exemplo, pelo cultivo de sementes transgênicas de algodão que divulgam ser mais resistentes a pragas e passam a descartar os ciclos da 
agricultura, utilizando o solo como fábrica. Entretanto, ambientalistas criticam tal posicionamento apresentando dados de malefícios à saúde dos trabalhadores e consumidores. Os últimos não atentam para o fato de quase $80 \%$ dos alimentos encontrados num supermercado serem produzidos com ingredientes geneticamente modificados. Para os agricultores, as consequências para a saúde física e mental são ainda piores e promovem altas taxas de suicídio entre produtores de algodão na Índia, já que eles vêem seus filhos acometidos por doenças e sem condições financeiras para o tratamento. Uma produtora ${ }^{\text {iv }}$ de algodão orgânico do Texas, EUA, fornece um depoimento no documentário alertando sobre as consequências para a saúde e o meio ambiente provenientes de plantas geneticamente modificadas, tendo em vista que 80\% do algodão produzido atualmente são geneticamente modificados.

Há também casos de doenças mentais e degenerativas em crianças a partir da água contaminada, por exemplo, por substâncias tóxicas como produtos químicos para tingir o couro que são despejados no rio, os efluentes de curtume, a poluição ambiental por ele provocada. Ao consumir a água da região, supostamente potável, as famílias do entorno se expõem a diversas doenças nocivas como a icterícia que pode evoluir para vários tipos de erupções cutâneas, câncer de fígado, hepatite e cirrose. O filme mostra os casos de icterícia recorrentes na cidade de Punjab, na Índia, local onde a maioria do algodão indiano é cultivado e também principal consumidor de pesticidas do mundo. O doutor Pritpal Singh apresenta no documentário os efeitos dos produtos químicos na saúde humana a partir de seu estudo que demonstra grande aumento do número de defeitos congênitos, cancros e doenças mentais na região com cerca de 70 a 80 crianças em cada aldeia com retardo mental grave e deficiência física.

Depois das atividades petrolíferas, a indústria da moda é a segunda maior poluente da Terra desde a sua produção até o descarte. Cerca de 125 milhões de pessoas no mundo têm a saúde comprometida pela poluição tóxica em virtude da atividade industrial. Chumbo, cromo, mercúrio, amianto, cádmio e compostos orgânicos voláteis são os poluentes mais comuns e mais mortais do planeta de acordo com o World's Worst Pollution Problems Report ${ }^{20}$, documento elaborado com base nas informações coletadas por um programa de identificação de locais tóxicos implementado pelo Instituto Blacksmith ${ }^{21} \mathrm{em}$ parceria com a Organização das Nações Unidas para o Desenvolvimento Industrial. Esse indicador estima, simultaneamente, o impacto da mortalidade e dos problemas que afetam a qualidade de vida. Por isso, é um importante instrumento para avaliar o estado de saúde da população.

Por conta das dívidas crescentes, houve um aumento de casos de suicídios entre agricultores de algodão na Índia, contabilizando 250 mil nos últimos 16 anos, cerca de um agricultor a cada 30 minutos. Essas fatalidades e demais consequências, é claro, não se restringem aos agricultores do algodão. Elas abrangem os trabalhadores de canaviais e qualquer outra produção agrícola que utilize algum tipo de agrotóxico.

Contudo, nenhuma ação efetiva tem sido realizada para contrapor esse fenômeno que atua como uma sentença de morte que está encurtando a vida de milhares de famílias, conforme relato da produtora de algodão orgânico supracitada que afirma que os agrotóxicos de sementes transgênicas contribuem para o aumento de casos de câncer entre os agricultores da região nos últimos anos, entre eles, seu cônjuge falecido. Embora ela não possa comprovar cientificamente sua afirmação, tais fatos não refutam seus argumentos. Da mesma forma, estudos realizados com animais e divulgados pelo site The Organic Prepper ${ }^{22}$ relatam que uma dieta à base de organismos geneticamente modificados causa tumores de tamanhos elevados, morte, falha prematura de órgãos, lesões gástricas, reações alérgicas graves e danos hepáticos e renais. Essa informação vai de encontro ao posicionamento oficial da empresa líder na patente de sementes transgênicas, a Monsanto, que "justifica" seu "negócio" pela necessidade de suprir a demanda da fome mundial. A realidade observada no documentário analisado é diferente. Com o aumento do valor de sementes geneticamente modificadas, além de arcar com esse custo, os produtores têm que comprar mais

iv O filme não menciona em momento algum o nome da agricultora de algodão do Texas, EUA. 
pesticidas e fertilizantes para eliminar as pragas consideradas como narcóticos ecológicos. A partir disso, é uma questão de tempo até contaminar o solo.

As condições degradantes de trabalho de mão de obra escrava também levam ao suicídio de trabalhadores da empresa de tecnologia chinesa Foxconn, que abastece grandes corporações como a IBM e a Apple, que constantemente lançam produtos que corroboram a moda em tecnologia para o varejo. Os suicídios dos funcionários da Foxconn atingiram uma reincidência a tal ponto, que os empresários instalaram uma rede de proteção a partir do segundo andar na parte externa do prédio. Fotos da fachada com tal rede circulam livremente na internet para o conhecimento de todos. O mais interessante é constatar que a concepção de escravidão contemporânea, em muitos casos, está ligada a conceitos teleológicos ${ }^{\mathrm{v}}$, já que a escravidão não se ajusta às concepções de democracia e de capitalismo sustentadas na sociedade pós-moderna ${ }^{24}$, ou seja, muitos desses trabalhadores não se acham ou não se sentem escravos. Em um das cenas do filme, a personagem Shima descreve os socos e pontapés no estômago recebidos, quando ela e outras funcionárias iniciaram uma organização com viés sindical para reivindicar direitos trabalhistas e melhores condições laborais para todos. Após apresentar a lista de exigências aos diretores, o grupo foi trancado em uma sala, e os próprios diretores e mais de 30 homens iniciaram as agressões físicas com cadeiras, pedaços de madeira, tesouras e outros objetos.

As condições alarmantes de regime intenso de trabalho em locais sem estrutura física levaram à morte de cerca de mil trabalhadores no caso do desabamento do prédio Rana Plaza em Dhaka, Bangladesh, em 2013, onde funcionavam quatro fábricas de roupa independentes com cerca de cinco mil empregados, que revendiam seus produtos para lojas varejistas do Ocidente de marcas do Grupo Benetton, The Children's Place, Primark, Monsoon, DressBarn e H\&M, conforme apresentado no documentário analisado. Segundo o Global slavery index ${ }^{25}$, de 2014, o Brasil está no $143^{\circ}$ lugar do ranking de países com maior prevalência da escravidão moderna, liderado pela Mauritânia, Uzbequistão, Haiti e Índia. As empresas clandestinas, "terceirizadas" por grandes corporações, mantêm seus trabalhadores em espaços superlotados, imóveis em situação de risco e péssimas condições físicas. E, no caso do desabamento do Rana Plaza, comprovou-se, de acordo com o filme, que autoridades locais haviam emitido pedido de evacuação aos donos da fábrica em virtude das condições impróprias do prédio para atividades laborais.

Em tempos de discussões sobre o retorno da terceirização da atividade fim de uma empresa, de acordo com o projeto de lei aprovado no Brasil em abril de 2015, as reflexões apresentadas neste artigo e as relações de trabalho escravo ou análogo na cadeia de produção do mundo da moda com suas consequências para cada setor envolvido retratadas no filme The True Cost se tornam sempre necessárias, enquanto a cultura da exploração de mão de obra constituir-se como prática contínua nas mais diversas sociedades das últimas décadas. Por que não definir como escravidão dos atores envolvidos na cadeia de produção e aquisição dos bens de consumo? Agricultores no cultivo da matéria-prima, artesãos de países subdesenvolvidos, profissionais "empreendedores" de suas carreiras, empresários em função do lucro desmedido por conta da concorrência e consumidores cada vez mais infelizes por não terem tempo de gozar a realização de suas necessidades, no sentido de desejos, em prol da criação de necessidades ilusórias, tomados pelo consumo como o fim, todos sucumbindo a depressões, solidão com dificuldades de relacionamento social, muitas vezes infantil, estresse, alcoolismo, entorpecentes, tumores, suicídios e mortes.

Ironicamente, o maior contraste de todos é, sem dúvida, a compreensão ou a incompreensão de que tais fatos ocorrem, sobretudo, em uma sociedade delineada pelo que se poderia chamar de excesso de informações.

\section{A publicidade social como possibilidade de resgate social no próprio sistema}

v O termo teleologia provém de dois termos gregos, telos (fim, meta, propósito) e logos (razão, explicação), ou seja, uma explicação ou razão de algo em função de seus fins ou explicação que se serve de propósitos ou de fins ${ }^{23}$. 
As razões que geram a decisão de consumir possuem origens diversas e podem ser por vínculos emocionais, condições financeiras, apresentação dos pontos de venda e relações comerciais de atendimento e com os contextos sociais nos quais o indivíduo está inserido. Após a decisão, se dá a compra e, em seguida, o uso e descarte, no caso de bens perecíveis. Em vista desse cenário, quais seriam outros caminhos possíveis?

Tomando como exemplo os cenários propiciados pelos empresários empenhados no lucro ilimitado, novas lógicas de comércio justo ${ }^{\text {vi }}$ podem surgir como uma alternativa positiva propagando, muitas vezes, a consciência ambiental, social e política. A start-up alemã Original Unverpacket ${ }^{26}$, por exemplo, apresenta uma proposta de novos hábitos de consumo com a inauguração em 2014 do primeiro supermercado do mundo sem embalagens. Embora para se sustentar em meio à concorrência tenha que contar com a publicidade do novo conceito de acordo com o qual os clientes necessitam levar seus recipientes, como potes plásticos e garrafas, para aquisição dos produtos, caso não queiram comprar novos, a internalização da nova cultura vai ao encontro das políticas mundiais de sustentabilidade que possuem como carro chefe a reciclagem e preocupação com o descarte de embalagens.

Outra técnica de publicidade social que pode vir a ser adotada pelos órgãos de vigilância sanitária dos países é tornar obrigatório a divulgação, pelas empresas, com destaque nas embalagens, de ingredientes geneticamente modificados na composição de seus produtos. Além disso, o Estado poderia criar políticas de incentivo fiscal para empresas de cultivo de produtos livres de agrotóxicos. Vale ressaltar que tal proposta se encaixaria no âmbito da publicidade social, uma vez que permitiria a participação efetiva da sociedade no processo de divulgação e de decisão de compra em vez de apenas uma comunicação de mão única estimulando o consumo esvaziado da necessidade "do uso" para a necessidade "de uso" inconsequente e desmedido. Ou seja, a publicidade seria social por envolver o consumidor final no processo crítico e complexo de consumo, tirando-o, portanto, do papel de simples comprador, mas alçando-o ao lugar de partícipe de uma prática que, no final das contas, vai gerar mais do que impactos socioeconômicos, mas pode vir a gerar consequências positivas ou negativas, conforme o desempenho prático da empresa e da marca. Nesse sentido, o cidadão pode ser o porta-voz das benesses e dos malefícios da marca com apoio e atuação da sociedade, do Estado e do próprio mercado que, se estiver na lógica do comércio justo, será beneficiado no decorrer e no fim do processo. Pode inclusive agregar um valor positivo à marca, uma vez que se ocupa e se preocupa com todos os envolvidos na circulação de mercadorias, desde a concepção até a distribuição dos produtos e serviços gerados.

A campanha global Make Trade Fair $^{27}$ é uma iniciativa de comércio justo que prima pela igualdade nas relações da cadeia de produção entre países de primeiro mundo e países subdesenvolvidos. Um cidadão que se cadastrar no seu site ${ }^{\mathrm{vii}}$ pode comprar camisetas ou enviar mensagens aos governantes. Um dos projetos apresentados em The True Cost e alinhados à política de Make Trade Fair é o People Tree da fundadora e diretora Safia Minney. A marca de moda de comércio justo começou suas atividades há mais de 20 anos no Japão e sustenta, até hoje, a preocupação com a qualidade de vida dos fornecedores e criadores. A forma como cada coleção é concebida se dá a partir das competências dos grupos de produção e com a perspectiva do desenvolvimento social e ambiental. Esse tipo de iniciativa consegue atingir e mobilizar diversos núcleos sociais ao redor do mundo, fortalecendo a causa e gerando conscientização social. Logo, existe uma prática comercial com publicidade social que se difere da publicidade comercial, uma vez que precisa da outra ponta, representada pelo cidadão comum que participa criticamente do processo de mudança da lógica da cultura do limite inatingível do consumismo imperante na sociedade contemporânea.

Divulgar cada vez mais esses espaços de dinâmicas para reflexão social envolvendo o consumidor de maneira consciente e crítica em todo o processo de consumo é papel da publicidade social por meio de

vi Trata-se de um movimento social e uma modalidade de comércio internacional que busca o estabelecimento de preços justos, bem como de padrões sociais e ambientais equilibrados nas cadeias produtivas, promovendo o encontro de produtores responsáveis com consumidores éticos ${ }^{4}$. 
novas tecnologias de mídia e inovação. Um exemplo emblemático da relação é o lançamento do aplicativo Moda Livre ${ }^{28}$ que revela marcas de roupas que já foram flagradas pelos fiscais do Ministério do Trabalho e Emprego (MTE) em casos de trabalho escravo. Vale ressaltar que marcas que utilizam produtos importados foram contempladas na avaliação. Mesmo com a veiculação recorrente de notícias na mídia sobre trabalho escravo, as mesmas marcas envolvidas no "negócio lucrativo de escravidão" na sociedade contemporânea continuam a elevar os valores de sua marca no mercado e a aumentar seus lucros de venda de bens de consumo. O Moda Livre auxilia o cidadão, ao listar as marcas relacionadas nesse contexto, incluindo a metodologia utilizada para coleta de dados e apresenta três categorias de classificação relacionadas aos níveis de combate ao trabalho escravo para as marcas que responderam a um questionário baseado em quatro indicadores: políticas, monitoramento, transparência e histórico.

A partir da "sociedade em rede" definida por Manuel Castells ${ }^{29}$, os criadores do aplicativo Moda Livre criaram um espaço para promover a reflexão necessária sobre o tema. "Como a informação é uma parte integral de toda atividade humana, todos os processos de nossa existência individual e coletiva são diretamente moldados [...] pelo novo meio tecnológico" ${ }^{29}$. Utilizar-se da técnica do aplicativo para tornar pública de forma mais estruturada e dinâmica as relações de empresas com o trabalho escravo moderno, sem dúvida, contribuiu diretamente para melhorar as chances de conscientização dos consumistas do ciberespaço. Há mesmo que se buscar um tratamento mais sofisticado para o senso comum, para aquilo que se sente no dia a dia [...]. Vive-se, hoje, um tempo de hiperconectividade, em que todos os elementos que compõem nossas vidas se apresentam de alguma forma conectados - sejam pessoas instituições, objetos ou mesmo significados."

O aplicativo Moda Livre, disponível desde 2013 no Google Play e na Apple Store, foi desenvolvido pela ONG Repórter Brasil ${ }^{\text {viii }}$, fundada em 2001 e composta por jornalistas, educadores e cientistas sociais. Todas essas iniciativas promovem, minimamente, uma reflexão crítica sobre como o consumo foi se tornando maestro que rege a orquestra social na lógica capitalista, se é que há lógica em consumir desenfreadamente sem considerar as consequências de tais atitudes, a não ser para o mercado. E sobre como a própria sociedade que se tornou vítima de suas decisões e atitudes pode reconverter o olhar e repensar o mundo direcionando-o para um formato mais justo.

\section{Considerações finais}

A produção de um documentário estruturado como The True Cost contribui grandemente, sobretudo, para expor a realidade e as consequências da cultura do consumo nos mais diversos campos, já que a lógica de mercado de escravidão da indústria têxtil é a mesma para os demais ramos com interface direta ou não, seja o da tecnologia, seja o da agricultura etc. Produções como essa contribuem para pensar sobre a lógica que foi sendo instaurada socialmente. A reflexão em si já seria uma forma de nos proteger de um retorno ao "estado de natureza" tão criticado por Thomas Hobbes. O homem não consegue conviver socialmente pelo benefício comum pelo fato de que ele só encontra a felicidade na comparação com outros homens ${ }^{30}$.

Até mesmo ações pontuais como a da Apple que doou parte de seus altos lucros da Black Friday para combater a Aids no final de $2014^{31}$, podem, mediante muitas ressalvas, ser consideradas válidas, ao menos, na perspectiva da publicidade envolvida como exemplo para outras empresas e na relação com o público assistido. Ainda que não seja uma ação tática de publicidade social.

Dessa forma, a publicidade social se torna um campo válido como meio de propagar iniciativas de comérciojusto com o objetivo de ganhar conhecimento, mobilização e força social por filmes, documentários,

viii A ONG Repórter Brasil é uma organização de referência nacional no combate ao trabalho escravo, na promoção do trabalho decente e na defesa de direitos sociais e ambientais. A organização tem duas áreas principais de atuação que reúnem todos os seus projetos: Jornalismo \& Pesquisa e Metodologia Educacional28. 
matérias jornalísticas, divulgação de petições públicas, aplicativos etc., fornecendo um conjunto de ferramentas essenciais para combater as forças motrizes desse 'espírito' brutal do capitalismo.

\section{Referências}

1. Morgan A. The True Cost Documentary [video]. Michael Ross, producer;2015.[citado 19 jun 2015]. Disponível em: https://itunes.apple.com/us/movie/the-true-cost/id989035329?ign-mpt=uo\%3D6.

2. Investing.com. Apple Inc (AAPL) [Internet]; 2014. Disponível em: http://br.investing.com/equities/applecomputer-inc-balance-sheet.

3. Fischmann R. Apple divulga receita de US $\$ 58$ bilhões e lucro de US $\$ 13,6$ bilhões no seu $2^{\circ}$ trimestre fiscal [Internet]; 2015. Disponível em: https://macmagazine.com.br/2015/04/27/apple-divulga-receitade-us58-bilhoes-e-lucro-de-us136-bilhoes-no-seu-segundo-trimestre-fiscal//

4. Cotera A, Ortiz H. Comércio justo. In: Cattani, AD. Laville JL, Gaiger LI, Hespanha P, coordenadores. Dicionário internacional da outra economia. Coimbra: Almedina; 2009. p. 60-67.

5. Bauman Z. Globalização: as consequências humanas. Rio de Janeiro: Zahar; 1999. p. 87-88.

6. Weber M. A ética protestante e o "espírito" do capitalismo. José Marcos Mariani de Macedo, tradutor. São Paulo: Companhia da Letras; 2004. p. 45, 47, 53.

7. Heller A. O cotidiano e a história. Carlos Nelson Coutinho e Leandro Konder, tradutores. São Paulo: Paz e Terra; 2004.

8. Pina S. A deontologia dos jornalistas portugueses, 2 ed. Coimbra: MinervaCoimbra; 2000.

9. Gorz A. O imaterial: conhecimento, valor e capital. Celso Azzan Júnior e André Gorz, tradutores. São Paulo: Annablume; 2005. p 38-39, 42, 45, 48.

10. Kotler P. Administração de marketing: análise, planejamento, implementação e controle. 5.ed., São Paulo: Atlas; 1998 p. 393.

11. Krüger, LM,Silva, HAS,Ensslin, SR. Brand Valuation: o dilema dos rankings das 100 marcas mais valiosas do mundo [Internet]. 2012. Disponível em: http://www.congressousp.fipecafi.org/web/ artigos $122012 / 185 . p d f$

12. BRAND FINANCE, 2015. Disponível em: http://www.brandfinance.com/images/upload/brand finance global 500 2015.pdf

13. Milward Brown. Top 100 most valuable global brands 2015 [Internet]. 2015. Disponível em:https:// www.millwardbrown.com/BrandZ/2015/Global/2015 BrandZ Top100 Chart.pdf

14. Forbes.The world's most valuable brands: Apple rises to the top again [Internet]. 2015. Disponível em: http://www.forbes.com/powerful-brands/

15. Schlosser E. Fast food nation: the dark side of the all-American meal. Boston: Houghton Mifflin; 2001.

16. Veja. Vendas da H\&M superam previsões e crescem 19\% em agosto [internet]. 2014. [citado]Disponível em http://veja.abril.com.br/noticia/economia/vendas-da-hm-superam-previsoes-e-crescem-19-em-agosto

17. Lipovetsky G. O império do efêmero: a moda e seu destino nas sociedades modernas. Maria Lúcia Machado, tradutora. São Paulo:Companhia das Letras; 2009. p. 43-44, 238.

18. Pompeu B. Os significados do consumir em tempos de redes sociais: comprar, vincular, curtir? In Atem GN,Oliveira T,Azevedo ST. Ciberpublicidade: discurso, experiência e consumo na cultura transmidiática. Rio de Janeiro: E-Papers; 2014. p.247-264.

19. Douglas M, Isherwood B. O mundo dos bens: para uma antropologia do consumo. Plínio Dentzien, tradutor. 2. ed. Rio de Janeiro: UFRJ; 2013.

20. Worst polluted report, 2012. Disponível em: http://www.worstpolluted.org/files/FileUpload/ files/2012\%20WorstPolluted.pdf

21. Blacksmith Institute, 2015. Disponível em http://www.blacksmithinstitute.org/. 
22. The organic prepper. Disponível em: http://www.theorganicprepper.ca/gmos-not-even-inmoderation-02072013

23. Villa, MM Dicionário de pensamento contemporâneo. São Paulo: Ed. Paulus, 2000.

24. Pereira, Marcela. O trabalho análogo ao escravo e os fundamentos da ordem econômica. Revista Publius, 2014: 6. Disponível em: http://www.periodicoseletronicos.ufma.br/index.php/rpublius/article/ view/3291/1322. Acessado em 04 de julho de 2015

25. Global slavery index, 2014. Disponível em http://d3mj66ag90b5fy.cloudfront.net/wp-content/ uploads/2014/11/Global Slavery Index 2014 final lowres.pdf

26. Hypeness, 2014. Disponível em: http://www.hypeness.com.br/2014/06/uma-start-up-alema-inaugura-oprimeiro-supermercado-sem-embalagens-descartaveis-no-mundo/

27. Oxfam CanadaANADA. Disponível em: http://oxfam.ca/our-work/campaigns/make-trade-fair

28. Moda Livre APP. Disponível em: https://itunes.apple.com/br/app/moda-livre/id768062605?mt=8

29. Castells, M. A sociedade em rede. 8. ed. São Paulo: Paz e Terra, 2005. p. 108.

30. Hobbes, Thomas. Leviatã ou matéria, forma e poder de um estado eclesiástico e civil. Os Pensadores. Tradução de João Paulo Monteiro e Maria Beatriz Nizza da Silva. São Paulo: 2. ed. Editora Abril Cultural, 1979: 105.

31. Canaltech, 2014. Disponível em: http://canaltech.com.br/noticia/apple/Apple-doara-parte-de-seuslucros-da-Black-Friday-para-combater-a-AIDS/\#ixzz3eEa1b10i 